\title{
RIO SÃO FRANCISCO: AS ÁGUAS CORREM PARA O MERCADO
}

\author{
SÃO FRANCISCO RIVER: WATERS RUN TO THE MARKET \\ RIO SÃO FRANCISCO: LAS AGUAS QUE CORREM PARA LO MERCADO \\ Claudio Ubiratan Gonçalves - UFP - Recife - Brasil \\ claudio.ubiratan@ufpe.br \\ Cristiane Fernandes de Oliveira - UFS - Itabaiana - Brasil \\ cadolive@uol.com.br
}

\begin{abstract}
Resumo
0 presente artigo lança vista sobre questões candentes que perpassam o rio São Francisco. Inicialmente são tratados aspectos do uso da água e dos investimentos públicos, ambos voltados para fins de produção energética e expansão das áreas irrigadas. Num segundo momento são ressaltadas a reestruturação produtiva do espaço do mercado a partir do Plano de Aceleração do Crescimento do governo Lula, e a continuidade das lutas de resistências visando a construção de espaços da esperança.
\end{abstract}

Palavras-chave: Rio São Francisco. Geopolítica. Água. Reestruturação produtiva. Geografia econômica.

\section{Abstract}

The present work approaches ardent questions about San Francisco river. Water use and public investments aspects are initially treated, both to energetic production and expansion of irrigated areas. In a second plan, productive restructuring of space from the Growth Acceleration Plan of Lula government and the continuity of resistances fights aiming the construction of hope spaces are considered.

Key words: São Francisco River. Geopolitics. Water. Productive restructuring. Economic geography Brazil.

\section{Resumen}

En este artículo se considera temas candentes que atraviesan el río San Francisco. Inicialmente aspectos son tratados del uso del agua y de las inversiones públicas, dirigidas hacia finales de la producción energética y de la extensión de las áreas irrigadas. En un segundo tiempo son subrayó la reorganización productiva del espacio del mercado desde del plan de la aceleración del crecimiento del gobierno Lula da Silva, y la continuidad de las luchas de resistencias que tienen como objetivo la construcción de los espacios de la esperanza.

Palabras clave: Río San Francisco. Geopolítica. Água. Reestructuración productiva. Geografía econômica Brazil.

\section{Introdução}

Ao se tratar a questão hídrica no Brasil, torna-se imperativo a abordagem sobre a questão do rio São Francisco. Isto se deve ao fato de que, em meio à abundância de água no país, ao menos no que se refere à quanti- 
dade disponível, é possível constatar o contraste de acesso à água no caso do nordeste brasileiro. Essa oposição quanto ao acesso não está associado unicamente às características naturais climáticas, mas principalmente, às decisões geopolíticas associadas à manutenção da hegemonia latifundiária e do mercado da água.

Desse modo, o processo de ocupação territorial e expansão da produção do espaço capitalista nas margens do rio São Francisco, sobretudo nos dois últimos séculos, ocorreu com a desconfiguração tanto da paisagem quanto do modo de vida ribeirinho. Tal ação patrocinada direta ou indiretamente pelo Estado incide na desestruturação das relações homem - homem e homem - natureza.

No século XIX, a Geografia foi utilizada na região como eficiente campo de reconhecimento do território e no registro de minuciosas descrições de suas gentes, fauna e flora. No século seguinte, as ações e discursos não somente do Estado, mas também da sociedade, focaram de modo equivocado na problemática do clima e nas políticas hidráulicas de combate a seca.

O período atual traz de forma renovada os apelos do Estado através de uma política de inspiração autoritário-desenvolvimentista materializada no PAC (Plano de Aceleração do Crescimento). Por outro lado identificamos iniciativas de organizações da sociedade civil juntamente com movimentos sociais como o MST (Movimento Sem Terra) e MPA (Movimento de Pequenos Agricultores) na construção de uma articulação de propostas de convívio com a caatinga e na luta social por terra e água.

Neste sentido, o discurso do desenvolvimento com base no uso das águas do rio São Francisco, apesar de ter como pano de fundo a resolução do acesso à água, produção agrícola irrigada, está voltado, essencialmente, para fim de atendimento do mercado externo à região nordestina. João Suassuna (2001), tem se destacado em suas abordagens sobre o rio São Francisco e sobre o projeto de transposição. Segundo o autor, são várias questões que esbarram nos interesses privados, como por exemplo: a outorga dos recursos hídricos nas áreas a serem abastecidas, as desapropriações e indenizações, a gestão e manutenção da infra-estrutura (canais, tubulações, etc), a gestão da água, entre outras.

Neste trabalho, procuraremos levantar alguns aspectos para discussão acerca dos usos múltiplos na bacia do rio São Francisco e dos impactos ambientais e sociais impostos às regiões ribeirinhas, principalmente, tendo em vista a preponderância de alguns usos sobre os demais. 


\section{Água e usos múltiplos}

A água, compreendida como bem de uso comum, é essencial à reprodução da vida em todos os seus aspectos e por isto, deve ser utilizada com parcimônia e cuidados quanto à sua conservação e ciclagem.

Dentre os usos múltiplos da água amplamente reconhecidos, temos o abastecimento público, o saneamento básico, a geração de energia, o uso da água para processos industriais, a irrigação, a pesca, o lazer e a navegação.

A Lei ${ }^{\circ}$ 9.433, de 1997, instituiu a Política Nacional de Recursos Hídricos e criou o Sistema Nacional de Gerenciamento de Recursos Hídricos. Segundo a Agência Nacional de Águas (ANA), a partir da Política Nacional de Recursos Hídricos, "os diferentes setores usuários de água passaram a ter igualdade no direito de acesso a esse bem". Estabelecendo-se, entretanto, que em caso de situações de escassez a prioridade de uso da água no Brasil é o abastecimento público e a dessedentação de animais.

Retomando a questão dos usos múltiplos da água do rio São Francisco, é importante perceber que o estabelecimento legal da cláusula da escassez, priorizando o uso de abastecimento, potencializaria conflitos.

Com vastas áreas caracterizadas pelos domínios do semi-árido, a região da bacia do rio São Francisco, pode ser considerada uma área onde predomina a escassez de água. Assim, a outorga para uso da água deveria priorizar os projetos de abastecimento ao invés daqueles voltados aos grandes projetos de irrigação.

Segundo dados divulgados pela ANA, em janeiro de 2008, foram emitidas mais de 1000 outorgas de projetos de irrigação. Grande parte destas propostas apresentam áreas cultivadas acima de 50 ha. Tendo em vista a grande expansão da cultura irrigada e dos agronegócios para a região do oeste nordestino e o estabelecimento legal de que a prioridade de uso da água em caso de escassez é para fim de abastecimento a retomada do projeto de transposição se tornou possível, perante a lei e perante toda a sociedade apropriando-se do discurso de expansão do abastecimento público.

Neste sentido, a base do discurso promovido pelo Ministério da Integração Nacional é o abastecimento de 390 pequenas, médias e grandes cidades do agreste e semi-árido nordestino, incluindo as dos estados de Pernambuco, Ceará, Paraíba e Rio Grande do Norte. Para isto, quando forem concluídas todas as obras envolvidas no projeto de transposição do rio São Francisco, serão retirados $26,4 \mathrm{~m}^{3} / \mathrm{s}$, reduzindo ainda mais a vazão mínima atual de $1.300 \mathrm{~m}^{3} / \mathrm{s}$. 
É importante lembrar a evolução das vazões mínimas estipuladas para o rio. Dentre os trabalhos que abordam dados sobre este aspecto pode ser citado o de Suassuna (2000) lembrando que para propiciar a operação da usina de Sobradinho, a vazão mínima do rio foi reduzida para cerca de $2100 \mathrm{~m}^{3} / \mathrm{s}$. Em 2008, segundo a ANA, a vazão mínima prevista diminuiu para $1.300 \mathrm{~m}^{3} / \mathrm{s}$, tendo chegado a $1.110 \mathrm{~m}^{3} / \mathrm{s}$ entre dezembro de 2008 e abril de 2009.

A diminuição da vazão do rio mostra que as demandas pelas águas aumentaram nos últimos anos. Esta evolução no uso das águas do rio São Francisco esteve ligada tanto à necessidade de aumento da capacidade energética, pela via da hidroeletricidade com a construção de grandes reservatórios, como aos grandes projetos de irrigação. O uso múltiplo da água, advindo das demandas energéticas e da irrigação, compõe um histórico recorrente na exploração do rio São Francisco, bem como de outros recursos hídricos brasileiros.

Neste contexto, entre 1973 e 1979 foi construída a usina hidroelétrica de Sobradinho, concorrendo também para o desenvolvimento, a partir da década de 1970, dos grandes projetos de irrigação, como o caso da região de Petrolina e Juazeiro. É importante notar que, apesar de ter sido entre a década de 1960 e 1970 que ocorreu o maior crescimento percentual de investimentos em irrigação, tendo havido um decréscimo em termos relativos nas décadas posteriores, entre 1985 e 1995 houve uma retomada dos investimentos em irrigação, sendo que, neste período, houve crescimento da área irrigada na região nordeste do Brasil de 104,9\%.

A região nordestina só perdeu neste mesmo período em termos de crescimento da área irrigada para a região centro-oeste, o que é notável considerando que a região não possui tanta disponibilidade de água.

Ao se considerar a questão da irrigação não se deve perder de vista que boa parte destes projetos está associada à extração de água do rio São Francisco, que é perene, exceção na região. Com a construção de barragens e com o incremento das áreas irrigadas corre-se o risco de diminuir ainda mais a vazão do rio em sua foz e isto implica em consequências ao meio natural diretamente ligado ao rio e às comunidades que vivem do que o meio natural lhes oferece como a possibilidade de cultura de inundação, pesca, coleta de crustáceos, etc. 


\section{Os impactos e o descaso nos investimentos públicos}

São vários autores que apontam para os impactos relacionados às alterações impostas aos recursos hídricos, dentre eles, Marques (2003) aponta o caso do avanço do mar sobre áreas continentais, na foz do rio São Francisco devido à diminuição da força das águas do rio, pela diminuição de sua vazão. Muehe (2005) por sua vez, explica que além da diminuição da vazão das águas, também o processo contínuo de transporte de sedimentos pelas águas dos rios contribuem para constituir barreiras submersas que impedem o avanço das águas marinhas nas áreas estuarinas. Quando estes sedimentos ficam retidos à montante, nos reservatórios, o avanço das águas marinhas se acelera, invadindo áreas que antes eram protegidas pela dinâmica equilibrada entre o encontro das águas do rio e o mar. O caso do avanço do mar sobre o povoado Cabeço, município de Brejo Grande - SE na foz do rio São Francisco é um claro exemplo deste desequilíbrio.

Cerca de 500 famílias tiveram que ser realocadas para os povoados próximos de: Saramém, Resina, Brejão dos Negros e as que ainda ocupam a área correm risco de perder suas casas pelo acelerado e contínuo avanço do mar sobre a área.

O avanço do mar sobre áreas do estuário também altera a salinidade das águas, sendo que peixes de água salgada têm sido encontrados em áreas anteriormente de predomínio de água doce. A salinização dos estuários e dos aquíferos nas áreas de contato tem impactado as comunidades ribeirinhas, que são obrigadas a modificarem suas atividades sob a ameaça de perderem sua produção ou sua forma de sustento.

Santos (2008) discorre sobre os impactos socioambientais da salinização da água do rio sobre as cultura do arroz em Porto da Folha-SE, lembrando que grande parcela dos produtores foram obrigados a abandonar a atividade. Sob o aspecto da piscicultura tem havido perda de biodiversidade, já que muitas espécies que dependiam da piracema, retornando para desova em áreas à montante do rio, não conseguem mais fazê-lo, seja devido aos represamentos, ou devido à alteração na turbidez, na temperatura e na composição química, devido o uso e despejo excessivo de agrotóxicos e de esgotos sem tratamento nas águas.

Os usos múltiplos na realidade se reduzem a poucos, como o uso para fins de produção energética e para irrigação. Os demais usos são ínfimos e muitos deles têm desaparecido devido aos impactos gerados pelos primeiros. Assim, enquanto a pesca, a navegação, as pequenas culturas de inun- 
dação perdem força, o agronegócio da fruticultura irrigada cresce e com ele novas demandas por energia.

Quanto ao uso da água para fim de saneamento básico e de abastecimento de água, que são necessidades reais e crescentes, especialmente nas aglomerações urbanas, pode-se afirmar que ainda são necessários muitos investimentos para o alcance de condições adequadas. Em se tratando da bacia do rio São Francisco, os volumes de esgotos produzidos, coletados e tratados são de $669 \mathrm{mil} \mathrm{m}^{3} / \mathrm{ano}, 239 \mathrm{mil} \mathrm{m}^{3} / \mathrm{ano}$ e $81 \mathrm{mil} \mathrm{m}^{3} / \mathrm{ano}$ respectivamente.

Ainda, de acordo com informações disponibilizadas pelo Comitê da Bacia Hidrográfica do Rio São Francisco, somente 52,5\% dos esgotos da Bacia são coletados e $20,7 \%$ deste total é tratado. Isto implica em comprometimento das águas dos rios da bacia com perda da qualidade para fim de uso, especialmente o de consumo humano.

As principais demandas de uso da água, excluído o uso energético, atualmente estão, atualmente, assim distribuídas na bacia do rio São Francisco:

\begin{tabular}{|c|c|c|}
\hline Uso humano $\left(\mathrm{m}^{3 /} \mathrm{s}\right)$ & Irrigação e uso animal $\left(\mathrm{m}^{3 /} \mathrm{s}\right)$ & Uso industrial $\left(\mathrm{m}^{3 /} \mathrm{s}\right)$ \\
\hline 28 & 167 & 29 \\
\hline
\end{tabular}

Fonte: SMARH-SE/Comitê da Bacia Hidrográfica do rio São Francisco, 2009.

As altas e crescentes demandas de água para fim de irrigação demonstram que a área cultivada tem sido ampliada. Neste sentido, não deve ser desprezado o impacto referente ao uso de agrotóxicos, com consequente contaminação dos cursos d'água da bacia.

Tendo em vista o quadro de supremacia do uso da água para fim de irrigação sobre os demais usos, e considerando que a questão da escassez da água não deve ser compreendida somente sob o aspecto da quantidade, mas também da qualidade das águas, sejam elas superficiais ou subterrâneas, torna-se urgente a necessidade de revisão das prioridades de investimentos públicos. Neste sentido, a água, para fim de abastecimento, deve ser universalizada da melhor forma possível, sendo que os investimentos em saneamento básico são emergenciais para a garantia da qualidade dos recursos hídricos. 


\section{Um rio refém do mercado}

Abaixo, descrevemos situações constatadas no baixo curso do rio São Francisco a partir da imposição da força do grande capital na dinâmica local.

No início de 2009 a ANA (Agência Nacional de Águas) reduziu a vazão mínima do rio de $1300 \mathrm{~m}^{3} / \mathrm{s}$ para $1100 \mathrm{~m}^{3} / \mathrm{s}$ abaixo das barragens de Sobradinho (BA) e Xingó (SE), com a justificativa de guardar água para segurança adicional ao sistema elétrico. Todavia, segundo informações obtidas através de técnico da própria estatal, a CHESF (Companhia Hidroelétrica do São Francisco) estava vendendo energia para Argentina, ao mesmo tempo em que ocorria o defeso (período de reprodução da ictiofauna) no qual os pescadores são impedidos de pescar. Em decorrência desses fatos, os camponeses e pequenos irrigantes tem o cotidiano modificado por aproximadamente três meses. Como alternativa a este quadro, os movimentos populares, ambientalistas e estudiosos defendem a gestão da barragem com vazão ecológica que proporcione condições de vida no rio, permitindo manter as atividades ribeirinhas e contenção do avanço do mar que já adentrou aproximadamente cerca de $50 \mathrm{~km}$.

Se por um lado o Estado e o Mercado enxergam na água um recurso/ produto estratégico na acumulação capitalista, aos agricultores e pescadores estão reservadas as seguintes opções: migração sazonal aos grandes centros em busca de emprego e para aqueles que resistem o emprego de piscicultor no cultivo de espécies exóticas nos tanques de camarão, tilápia, tambaqui ou até mesmo a espécie nativa do surubim. As empresas do setor vêm constatando que o pescador artesanal ribeirinho não serve para piscicultor, pois sua prática é extrativista, e foram buscar nas caatingas, no criador de bode e pescador dos açudes sertanejos a solução para o criatório das espécies exóticas. Sem esquecer que a alimentação fornecida aos peixes de cativeiro é à base de ração com soja transgênica.

Outro aspecto que merece destaque no tocante ao hidronegócio está relacionado à ampliação da rodovia Linha Verde que já interliga todo o litoral baiano. Objetiva-se priorizar o turismo pelo litoral do nordeste, bem como a construção de uma ponte entre os municípios de Brejo Grande - Piaçabussu, ligando Sergipe a Alagoas.

A existência de conflitos por terra na foz do rio São Francisco a partir de duas situações distintas demonstra as formas de manifestação do capital imobiliário e como tem início seu processo de territorialização. 
Na primeira situação, vejamos como tem ocorrido o dia-a-dia desse embate. Temos no povoado Resina, no município de Brejo Grande (Sergipe), a presença de capangas que estiveram na comunidade de pescadores no ano de 2008 e destruíram, na ocasião, 12 barracos de pessoas que aceitaram, após muita pressão da Norcon (empresa do setor imobiliário), a transferência para um conjunto habitacional na comunidade de Saramém, em Brejo Grande. Relatos dos pescadores informam que capangas atearam fogo em três casas, em redes de dormir, redes de pesca e demais pertences dos posseiros: "Foi tanto fogo que a gente ficou desnorteado; os adultos e as crianças ficaram tudo sufocados com a fumaça; eles pegaram fachos de fogo e não teve piedade" (Seu Luiz).

Na segunda situação, também em Brejo Grande, no povoado Brejão identificamos algo similar. De um lado famílias de brasão com poder de influência no sistema político-jurídico local se apresentaram como proprietários do terreno onde estão situadas as casas e as terras de cultivo comum. De outro lado famílias quilombolas organizadas e tensas com as hostilidades geradas pelo ambiente de conflitos por terras. Também ocorrem conflitos no interior do povoado entre grupo favorável ao reconhecimento da identidade quilombola e outro grupo contrário ao processo. $\mathrm{Na}$ verdade o ambiente de conflitos foi gerado pelos supostos donos de terras que na iminência de terem as terras, que foram exploradas anteriormente com cana-de-açúcar, regularizadas e identificadas como terras de negros remanescentes de quilombos se armaram de artifícios jurídicos para impedir tal acontecimento.

\section{PAC da transposição}

Mesmo ocorrendo divergências de natureza política, interesses econômicos implícitos e ausência de consenso técnico entre os especialistas no assunto e técnicos do governo, as obras de integração de bacias hidrográficas ou transposição já foram iniciadas.

A execução de obras na área militarizada do rio São Francisco tendo em vista o crescimento ilimitado na perspectiva utilitarista sem o devido respeito aos limites da natureza, e com descaso aos direitos territoriais das reservas indígenas, de terras quilombolas e de pequenos agricultores, faz parte de um modelo ultrapassado de desenvolvimento econômico.

$\mathrm{O} 2^{\circ}$ Batalhão de Engenharia de Construção ( $2^{\circ} \mathrm{BE}$ Cnst) foi deslocado de Teresina/PI e levantou destacamento, em território reivindicado 
pelo povo Truká, no município de Cabrobó-PE. O mesmo é responsável pela implantação das obras de 2.080m do Canal de Aproximação à Estação de Bombeamento EBI-01 e da Barragem de Tucutu (eixo norte do projeto), num prazo de 15 (quinze) meses a contar do início das obras em setembro de 2008. Até março de 2009, momento em que foi possível coletar dados de pesquisa, a obra já havia avançado cerca de 6 km em direção ao Ceará.

Em entrevista realizada com D. Adriano Ciocca Vasino, bispo de Floresta/PE, constatamos que as obras do eixo leste avançaram aproximadamente $20 \mathrm{~km}$ desde a tomada d'água, somente em terraplanagem, não há revestimento dos taludes. A obra avançou até a reserva biológica de Serra Negra, território Pipipã e Kambiowá. Depois da reserva a obra é retomada de Ibimirim a Sertânia, também localizados em Pernambuco.

Neste sentido, o plano de aceleração do crescimento que também inclui significativas obras de engenharia no rio São Francisco, segundo o discurso oficial do governo, consiste em investimentos em projetos de infraestrutura, logística e energia para facilitar a aceleração do desenvolvimento sustentável, aumento da produtividade e a superação dos desequilíbrios regionais e sociais. Capitaneado essencialmente pelos ministérios da Casa Civil, Planejamento, Fazenda e Integração Nacional, prevê também a urbanização e o saneamento de áreas consideradas carentes, revitalização de bacias hidrográficas e investimentos na expansão, manutenção e modernização dos serviços rodoviário, marítimo, fluvial e ferroviário, além de ampliação de portos e aeroportos.

Traduzindo tais investimentos em valores atuais de moeda nacional, estimam-se investimentos da grandeza de R $\$ 503$ bilhões em infraestrutura entre 2007-2010. Para a área energética serão R \$ 274 bilhões. A intenção dos formuladores do plano é desembolsar R $\$ 287$ bilhões provenientes do governo federal e das estatais, ficando $\mathrm{R} \$ 216$ bilhões para iniciativa privada (PPP). Especificamente para o projeto da transposição estão previstos no PAC R \$ 6,6 bilhões, do total de R \$ 12,6 bilhões a serem investidos em obras de infraestrutura hídrica.

Portanto, o projeto de aceleração do crescimento no discurso e na prática tem demonstrado forte influência da ideologia nacional-desenvolvimentista que orientou as intervenções econômicas em pleno regime militar.

Conforme nos alerta Goméz (2007), a Geografia detém um papel fundamental na desconstrução do desenvolvimento. Ou seja, a desconstrução do desenvolvimento elaborado pelo pós-desenvolvimento, portanto, responde à finalidade de mostrá-lo como historicamente construído e racional- 
mente exótico para a maior parte da humanidade, enfim, parcial apesar de sua pretensão de universalidade.

Nesta perspectiva o PAC se enquadra no rol do ajuste estrutural do território ao capital e como processo da ideologia do desenvolvimento local. O discurso do desenvolvimento, longe de ser uma questão da promoção do bem-estar da sociedade, tem um caráter ilusório ao cumprir uma importante função ideológica: a legitimação das relações de produção capitalistas que operam as diferenças, ou, em outras palavras, dirigem a produção da pobreza (LISBOA \& CONCEIÇÃO, 2007).

\section{Construção de espaços da esperança}

Já perdi o otimismo, mas não perdi a esperança.

Pe. Tiago, Pastoral da Terra/PE

A frase emblemática de um dos representantes da pastoral da terra na região nordeste denota um retrato dos movimentos sociais no tempo presente e de certo modo reforça a luta no Velho Chico. Segundo o franciscano D. Luiz Cappio, um dos maiores defensores dos diferentes povos do Velho Chico, o projeto da transposição pode ser comparado a um computador cheio de vírus. Ou seja, as ações técnicas são pensadas de forma compartimentada e não possuem nenhum tipo de interação/ligação entre natureza, cultura e sociedade. O projeto se encontra viciado por não priorizar o desenvolvimento humano e os problemas sociais mais latentes como: falta de saneamento básico, investimentos em educação, saúde e segurança pública. Qual o antídoto para o vírus? Pensar e entender o espaço geográfico em sua totalidade, consultar e escutar a população envolvida direta e indiretamente, técnicos, bem como consultar o Congresso Nacional. Neste sentido é preciso exterminar o vírus e reinstalar todos os programas do computador.

Não obstante, está em andamento a construção de espaços de resistências que são, ao mesmo tempo, espaços de diálogo e de fortalecimento das lutas sociais por autonomia e identidade territorial. A mobilização em torno da transposição despertou os povos - indígenas, quilombolas, pequenos agricultores, artesãos, pescadores, lavadeiras, educomunicadores e outros. As inúmeras mobilizações e ocupações de espaços públicos como expressão de descontentamento com andamento da política de governo permite tomada de consciência do povo ribeirinho. 
Os mesmos avançam na tessitura de articulação de redes de solidariedade e de circulação de informações com apoio de ONGs, igrejas, sindicatos e entidades que perceberam a necessidade e importância de organização coletiva em torno da defesa do bem comum: água, terra e identidade. Como exemplos, a APOINME - Articulação dos Povos Indígenas do Nordeste, Minas Gerais e Espírito Santo, ganha novo ânimo. Ainda criada em 1990, surge com o objetivo de lutar pela recuperação dos territórios tradicionais e cobrança por políticas públicas relativas à educação, saúde, desenvolvimento e sustentabilidade dos povos indígenas perante o Estado brasileiro, e no momento incorporou também a luta pelo rio. E a articulação popular do baixo, submédio, médio e alto São Francisco surgiu em 2006 na perspectiva de organizar agenda de atividades, jornada de lutas, traçar estratégias institucionais e iniciar uma forte campanha pela revitalização e contra a transposição do rio São Francisco. A rede é composta por dezenas de entidades e movimentos sociais espalhados principalmente pelo nordeste, mas, também pelo Brasil.

Outro aspecto de destaque na continuidade e visibilidade da construção dos espaços de resistência é a internacionalização da luta em defesa do rio São Francisco. A luta está internacionalizada através dos apoios institucionais, prêmios e títulos concedidos a D. Cappio, que em 2008 recebeu o prêmio da Paz concedido pela Pax Christi Internacional, que congrega 54 países. No primeiro semestre de 2009 o bispo de Barra na Bahia viajou a Alemanha e Áustria para participar de debates em Frankfurt, Berlim, Bonn, Bremen e Graz sobre energia, poder e fome. Em Freiburg recebeu o prêmio Kant de Cidadão do Mundo, concedido a cada dois anos. Foi o reconhecimento que D. Cappio teve pela sua luta em defesa dos direitos humanos e do rio São Francisco.

\section{Considerações finais}

Estamos vivendo um momento histórico em que a produção tem se mundializado exponencialmente, na qual indústrias e agronegócios de origens diversas, no que se refere ao domínio do capital, têm expandido suas fronteiras na direção dos territórios que lhe forem mais úteis. Este utilitarismo não se resume, exclusivamente, ao custo da mão de obra, mas além deste está em questão o acesso às fontes de recursos naturais essenciais à produção, como a água. 
Assim, enquanto grande parte da população continua sem acesso à água potável e às condições adequadas de saneamento básico, os recursos hídricos são disponibilizados em grandes volumes para o atendimento dos interesses privados. Também, os usos múltiplos que poderiam garantir o sustento de comunidades que historicamente se mantém em equilíbrio com o rio vão gradativamente desaparecendo devido aos impactos dos grandes empreendimentos.

Por todos estes motivos, torna-se imperativo resgatar as discussões sobre as prioridades de investimentos públicos, dentre os quais são evidentes as necessidades de desenvolvimento dos serviços de abastecimento de água e os de coleta e tratamento de esgotos para a melhoria da qualidade de vida das comunidades. Contudo, não se pode negligenciar outras necessidades, como a de fortalecimento de atividades que compunham os usos múltiplos e que, paulatinamente, foram sendo abandonadas em virtude dos impactos supracitados. Desta forma, as atividades ribeirinhas como a pesca, a navegação, o lazer, bem como o reconhecimento das tradições comunitárias devem ser estimuladas e promovidas, bem como o fortalecimento e a difusão do acesso à educação, que poderá transformar e contribuir na organização e mobilização dos envolvidos em prol da revitalização do rio São Francisco.

\section{Notas}

1 As discussões neste artigo resultam de reflexões realizadas no decorrer do I Encontro Sergipano de Geografia \& IV Simpósio sobre Ensino de Geografia ocorrido em janeiro de 2009 na cidade de Itabaiana-Sergipe e organizado pela Associação dos Geógrafos Brasileiros seção Aracaju.

\section{Referências}

GOMÉZ, Jorge R. M. Desenvolvimento em (des)construção: provocações e questões sobre desenvolvimento e geografia. In: FERNANDES, B. M. et al. (Orgs.) Geografia Agrária teoria e poder. São Paulo: Ed. Expressão Popular, 2007. p. 39-53.

LISBOA, Josefa B. \& CONCEIÇÃO, Alexandrina L. Desenvolvimento local como simulacro do envolvimento: o novo-velho sentido do desenvolvimento e sua funcionalidade para o sistema do capital. Terra Livre, São Paulo, v. 2, n. 29, p. 115-132, 2007.

MARQUES, Fabricio. As praias perdidas. Revista FAPESP, São Paulo, n. 92, p. 46-51, 2003. 
MUEHE, Dieter. Geomorfologia costeira. In: GUERRA, A. J. T. e CUNHA, S. B. da. (Orgs.) Geomorfologia uma atualização de bases e conceitos. 6. ed. Rio de Janeiro: Bertrand Brasil, 2005.

RIBEIRO, Manoel Bonfim D. A Potencialidade do Semi-Árido Brasileiro: O Rio São Francisco - Transposição e Revitalização - Uma Análise Técnica. Salvador: Ed. Livro técnico, 2007.

SANTOS, Reginaldo G. dos. Impactos sócio-ambientais à margem do rio São Francisco: um estudo de caso. Dissertação de Mestrado apresentada ao Departamento de Geografia da FFLCH/USP, São Paulo, 2008.

SUASSUNA, João. Transposição do São Francisco: alguns descaminhos. Recife: FUNDAJ/ DESAT, 2000, 10p.

DESAT, 2001, 4p.

. Transposição das águas do rio São Francisco: planejar é preciso. Recife: FUNDAJ/

Claudio Ubiratan Gonçalves - Geógrafo e Professor Adjunto da Universidade Federal de Pernambuco.

Cristiane Fernandes de Oliveira - Geógrafa e Professora Adjunta da Universidade Federal de Sergipe.

Recebido para publicação em Setembro de 2009

Aceito para publicação em Novembro de 2009 